\title{
An Explorative Study on the Null Secondary Science Curriculum in Bangladesh
}

\author{
Tapashi Binte Mahmud Chowdhury ${ }^{1}$, Mohammad Nure Alam Siddique ${ }^{2 *}$ \\ ${ }^{1}$ Centre for Policy Dialogue, Lalmaha, Dhaka, Bangladesh, ${ }^{2}$ Institute of Education and Research, University of Dhaka, Bangladesh
}

*Corresponding Author: siddique.mna@du.ac.bd

\section{ABSTRACT}

The aim of this study was to identify the content of secondary Science curriculum excluded in teaching and learning activities, the reasons behind the omission and its impact on students' learning in the context of Bangladesh. This study used qualitative methodology. Eight teachers were selected and interviewed to investigate what they excluded from their teaching and what the reasons behind the exclusion were. Data were collected from participating teachers' students using a focus group discussion. Data collected from students and teachers were analyzed first. Then, purposefully selected curriculum developers, textbook authors, and teacher educators were interviewed to understand the impact of the null curriculum on students' learning. Analysis of data revealed that all the participant teachers excluded a chapter in Grades IX-X General Science textbook. This chapter included information about reproductive organs, physical and psychological changes during puberty, pregnancy, evolution, and related topics. Teachers argued that the topics were uncomfortable for them to teach, contradicted with religion, and students might misinterpret and practice unethical relationships if these topics were taught. However, the curriculum developers and the textbook authors asserted that including these topics would solve problems such as adolescent mistakes, child rape, child pregnancy, and distorted fantasies. This study concluded that excluding the chapter on adolescence, sexual and reproductive health and evolution obstructs achievement of students' scientific literacy.

KEY WORDS: null curriculum; scientific literacy; socio-scientific issues

\section{INTRODUCTION}

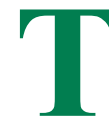
he "null or excluded" curriculum is a concept that was formulated by Eisner (1994) who described it as the topics which were not covered, taught, or included in the specific school curricula. Sometimes, it is not possible for a school to cover each topic included in the intended curriculum. Yet, omission of specific topics can cause the students to have incomplete learning experiences. The nature and extent of the null curriculum varies from school to school, but it has a huge impact on students' learning. In various contexts, it is argued that the null curriculum has a relation with socio-scientific issues (SSI). SSI are controversial social issues with conceptual or technological links to science (Sadler, 2004). These SSI are the topics which conflict with the society's values or cultures. However, according to current arguments in education, an unintentional omission of certain topics does not hurt the overall academic preparation of students because students are taught to use their inquiry skills and natural curiosity to explore and discover new topics that are not taught formally. Intentional omission, however, can lead to unexpected repercussions.

One of the aims of Science education in Bangladesh is to develop students' ability to make decisions in solving problems. The aims and objectives of Science education for Grades VI-X students emphasize this, "To facilitate the students in acquiring skills, scientific mindset and competencies to solve life-oriented problems using scientific process and inquiry system" (National Curriculum and Textbook Board [NCTB], 2012. p. 8).

The foregoing objective clearly shows that the Bangladesh curriculum intends to facilitate students' learning necessary for making decisions in their lives. This study was focused on whether any Science topic was intentionally omitted from teaching and how this omission affected students' learning that might be necessary for making decisions later in their lives.

The purpose of this study was to figure out the content of secondary Science curriculum excluded in teaching and learning activities, the reasons behind the omission and its impact on students' learning in the context of science education in Bangladesh. To meet this purpose, this study set the following research questions:

1. What topics are intentionally left behind in the enacted Science curriculum?

2. Why are these topics left behind in the enacted Science curriculum?

3. What is the impact of the null Science curriculum on students' learning?

\section{LITERATURE REVIEW}

\section{Aims of Science Education}

The aims of Science education are centered on two conflicting societal demands. These demands are (a) supply of future 
scientists and (b) development of scientifically literate citizenry (Fensham, 1985). Science educators currently recommend setting developing scientific literacy as the principal goal of school science education. Despite having a debate over the meaning of "scientific literacy," it is commonly seen as a vehicle to help tomorrow's adults to understand scientific issues (Reiss, 2007). The attributes of a scientifically literate person can be shown as in Figure 1.

As seen in Figure 1, it is evident that making informed decisions about the environment and their own health and well-being is one of the key abilities of a scientifically literate person.

\section{Science Education in Context of Bangladesh}

The education system in Bangladesh has several substreams: General Education, Madrasah Education (Education based on Islam), and Technical, and Vocational Education. Most of the students are in the General Education substream. Students of General Education, Madrasa Education and Technical, and Vocational Education study Primary Science at the primary level. All students study General Science as a unified compulsory subject up to Grade VIII. The contents include basic Science concepts from Physics, Chemistry, Life Science, and Earth and Environmental Science. This content is intended to create a foundation for students who want to study Science in further education. The General Science curriculum is also expected to promote scientific literacy for all students.

From Grade IX, students choose from three different groups: Science, Business Studies and Humanities. The Science students have to study Physics, Chemistry, Biology, and Higher Mathematics with an aim of studying Science in tertiary education. Since students of Humanities and Business Studies are not expected to pursue scientific professions, there is an Integrated Science named General Science for them which contains topics for enriching their scientific literacy.

\section{Null Curriculum}

As stated, the null curriculum is what is not taught (Eisner, 1994) in schools. Societal, schools' or teachers' personal values and priorities lead teachers to omitting parts of the intended curriculum from their lesson (Hildebrand, 2007). This omission might be unintentional or deliberately intentional (Figure 2).

When teachers intentionally exclude content, the probable reasons could be: The contradiction of that topic with his/her values, social insecurity, unnecessary for examinations, etc. According to Reiss (2007), it is clear that the place of personal values in the Science curriculum depends critically on one's views of the aim(s) of Science education. This particular view or value, if it contradicts with the topic to be taught, then teachers find it more convenient to exclude it. Both the teacher's competence and confidence also have an influence on the teaching of sensitive topics.

According to current arguments in education, an unintentional omission of certain topics does not hurt the overall academic preparation of students because students are taught to use their inquiry skills and natural curiosity to explore and discover new topics that are not introduced formally. However, when certain subjects or topics are left out of the overt curriculum, school personnel are sending messages to students that certain contents and processes are not important enough to study. In fact, according to Gehrke et al. (1992), a null curriculum is, "powerful by virtue of its absence" (p. 53). The existence of null curriculum surely depicts a gap in the attained curriculum. The intended curriculum, which is constructed based on the policy of a country, has some expected outcomes from the students and the presence of null curriculum shows the lack in achieving of those in the attained curriculum. The impact can be measured in two levels - students' personal development and overall social development. The aims of Education are thus obstructed by the presence of null curriculum.

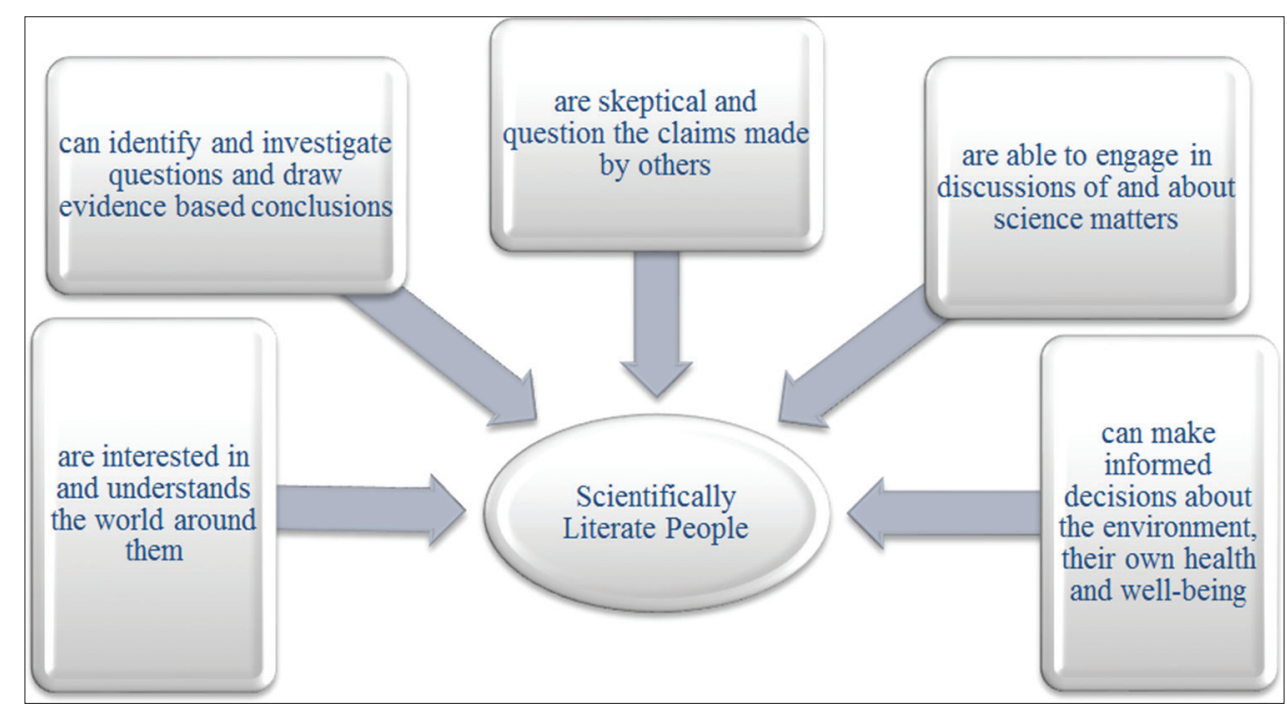

Figure 1: Attributes of scientifically literate people (From Goodrum, 2007) 


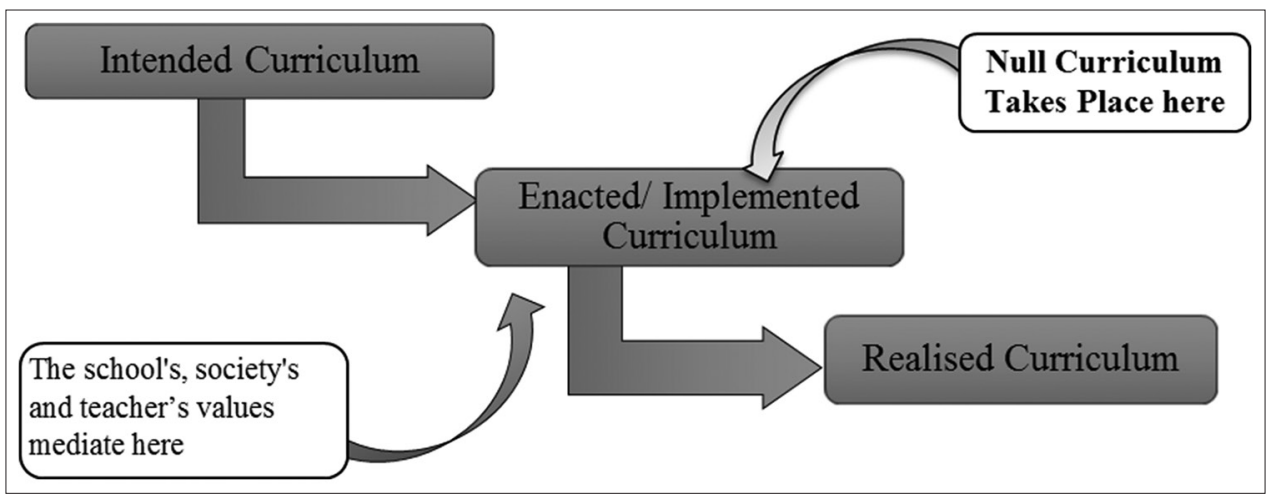

Figure 2: Conceptualizing null curriculum (Adapted from Hildebrand, 2007)

\section{METHODOLOGY}

This study raised the following research questions:

1. What topics are intentionally left behind in enacted Science curriculum?

2. Why are these topics left behind in the enacted Science curriculum?

3. What is the possible impact of the null Science curriculum on students' learning?

All three research questions require exploring unknown information. As these are related aspects, this study explored them in depth with a small number of individuals. Thus, qualitative methodology was the most suitable approach for this study (Creswell, 2008).

\section{Participants}

Eight teacher participants were chosen by convenience sampling method. According to Creswell (2008), the researcher selects participants considering their willingness and availability for the study. Teacher participants were chosen considering that they would provide useful information for answering the research questions of the study. Seven students from each of the teachers' classes, i.e., a total of 56 students were chosen randomly for eight focus group discussions (FGDs). The study used a purposive sampling technique that included snowballing methods to select expert participants who were engaged in curriculum development and textbook writing. One teacher educator, three curriculum developers and two textbook writers were selected this way.

Ethical aspects were duly considered in selecting participants though any official ethical approval is not required in doing educational research in Bangladesh. Voluntary participation, no harm to the participants, anonymity and confidentiality, deception, etc., are the points to consider for a social research involving humans (Babbie, 2002). In this research, participation was completely voluntary. We invited teachers of selected schools with an explanatory statement regarding their voluntary participation. Every teacher was briefed about possible risks and his/her right to withdraw himself/ herself from the study at any stage of the study without being disadvantaged. Students were selected for FGD who agreed to volunteer. They were selected in the absence of the class teacher so that they would not have any fear or thinking that participation or non-participation might affect their grades. Student participants in this study were from Grades IX to $\mathrm{X}$ with an age range of 15-16; permission was taken from guardians of students regarding students' participation in FGDs.

\section{Research Design}

This study consisted of two phases (Figure 3). In the first phase, information was collected from students and teachers regarding what topics were intentionally left out of teaching and learning. The study sought to identify whether there was any pattern in the neglected topics and why these teachers excluded the topics from the curriculum. The data gathered from the students and teachers were analyzed, then in the second phase the curriculum developers, textbook authors, and teacher educator were interviewed to explore the teachers' opinions and possible impact of the null curriculum on students' learning.

\section{Data Analysis}

Data collected from the students were analyzed first and then compared with the data from the teachers to address research question 1. After that, the teachers' opinions were analyzed and themes sorted out from their opinions. These teachers' opinions answered the second research question. In a similar way, collected data from curriculum developers, textbook authors and the teacher educator were analyzed thematically. The findings from the analysis of data are presented in the next section.

\section{Findings}

\section{Students' response on what topics were left out of} teaching

The students responded that there was no chapter left out from their textbook in classroom teaching. However, teachers admitted that they excluded a chapter titled "The Beginning of New Life" in their teaching. Students responded that they had learned the topics included in this chapter, however, it could not be accurately determined if they had learned this content from school or from other sources. Nevertheless, they all agreed that these topics were necessary to know for their age 


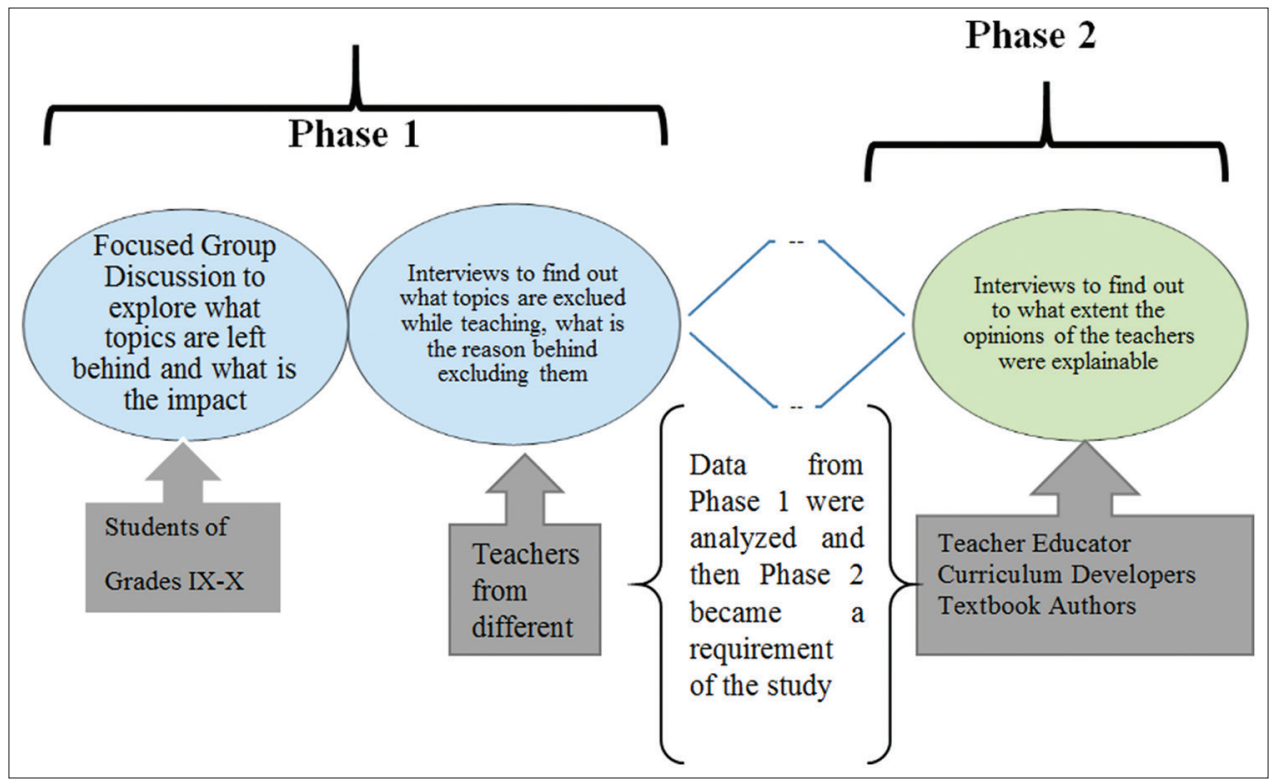

Figure 3: Research design for this study

as these topics have real-life relevance. Students' responses indicated that they had full knowledge about puberty changes and genital health.

\section{Teachers' response on what and why they leave out content}

Teachers' responded spontaneously to questions about what they excluded in their teaching. They excluded a chapter in General Science, which was designed for students of Humanities and Business studies. The reasons of excluding this chapter are explained below.

\section{Teachers feeling "uncomfortable"}

All the participating teachers excluded some topics in their class because they felt uncomfortable talking about those topics. They claimed that a chapter titled "The Beginning of New life" of General Science included some topics that were difficult for them to teach or talk about. Teachers thought that they belonged in a culture where anything related to sex education and genital hygiene was not openly discussed, even among family members. Hence, for these teachers, they found it difficult to teach these topics. For example, Ms. Khatun (all names are pseudonyms) said:

It is uncomfortable for the teachers to talk about these topics. They are our students; we cannot talk with them about wet dreams or male-female attraction. Our society does not allow us; besides, it is uncomfortable; teachers feel shy and obviously feel shy.

Ms. Begum also agreed to the above and specified some topics, which she felt uncomfortable talking about. She said, "There are some very small parts, very small, where the topic covers wet dreams, moustache or beard growth, and teachers feel shy to talk about these."

The teachers who were interviewed during the study were well experienced with established teaching careers. Hence, it could be assumed that the generation gap between the teachers and the students might have a great deal of influence for why these topics to be left out. It should be noted that in Bangladesh society, some words are usually avoided in public discussions, such as menstruations, wet dreams, ovary, and sperm. These words are consciously avoided or synonyms used. This may account for the reason for these teachers feeling uncomfortable discussing these topics with students.

\section{Classroom management would be an issue}

One of the reasons teachers mentioned for excluding the topics related to sex education and genital hygiene was that classroom management would become difficult. Five out of eight teachers said that if they discussed these topics, they would face unexpected interruptions such as students smirking and class dissolving into chaos. For example, Mr. Hossain stated:

We cannot talk about these in front of 60 young students. They will feel shy, and that makes us hesitate too. And then they start to laugh, smirk and the whole class in chaos. It's better for us to tell them to read these at home.

The students of Grades IX and X are expected to be aged between 15 and 16. In these years, students usually become acquainted with sexual emotions and attractions. Yet, talking about these topics is not forbidden just frowned on. Hence, talking about these topics for the students has not been formally done before, or no opportunities have been created to make a platform for talking about these. For this reason, teachers think that since these topics are new and arousing, the students might react differently than usual. As a result, the teachers might not be able to maintain the order of the classroom.

\section{It is the Parents' Duty, Not Teachers'}

When teachers were probed on the issue that if topics such as genital health and hygiene were not taught in schools, how 
students would learn about these; these teachers said that students would learn about them from their family. Seven teachers from the eight schools asserted that these topics should be discussed at home, with parents or elder brothers or sisters. Three of the teachers directly related to their own personal experiences and suggested that the family members have the responsibility to teach students these topics. Ms. Fatema noted:

We learned from our mother and aunties ... in our ages; we were not supposed to talk about these in public, our family members, told us, as much as we needed to know. Not anything unnecessary, like pregnancy or reproduction. It was a better way; you know ... It is supposed to be this way because it was a safe process, safe in a sense, it did not cause social disorder.

It can be seen from the above statement, that some teachers believed students should learn things in the same way they learnt about them. It is also evident that their upbringing has an effect on their teaching. Teachers also argued that students are closer to family members than the teachers; hence, it is easier for family members to talk about these topics. According to $\mathrm{Mr}$ Chowdhury, "Parents can make them understand better. They are close to the student more than us, so they will not feel shy or hesitated to talk about it."

Students experience puberty before they come to know the topic from a textbook, so teachers also assumed that the students already knew the necessary information about genital health from their family, or it would be taught to them by their family sooner or later.

\section{Students are Not Proper Aged to Know these Topics from Textbooks}

The teachers claimed that this chapter regarding adolescence was improper for the students of this age. Six teachers of the eight schools strongly claimed that the students were not "old enough" to know about this. Teachers were asked what would be the proper age for the students to learn this content. The answer ranged from three teachers stating 18 to 19 years; one said it is only necessary before marriage, and other teachers did not specify an age.

According to Ms. Begum, topics related to reproduction are not necessary for Class IX-X students. She believed, "Reproduction, pregnancy, and fertilization - these topics are very improper for a 15-16 years old girl. They can learn these topics before they get married when they are old enough."

However, the "proper age" was still vague. To some extent, they seemed to be self-contradictory. On the one hand, they said the students already knew about these topics from other sources; and on the other hand, they also think the students were not old enough to talk about these topics.

\section{Students Already Know from Electronic Media and Social Networking Websites}

Almost all the schools included in this study were in urban areas, and all the students of class 9 and 10 were supposedly internet users (as per their teachers' assumption). Five of the eight teachers thought the students already knew about this content from electronic media. And they said that is a major reason why they did not find it necessary to teach these topics in class. They focused more on Facebook and YouTube. The teachers seemed to have an opinion that use of internet has made the students already aware about the topics they were supposed to teach. According to Ms. Fatema, "These days, everything is open to all (i.e. accessible). Students use internet and see adult videos and already know more than us. What should we teach them?"

Four teachers related social networking websites to the acquisition of knowledge of the students on these topics. However, it was not clear from their opinion how social networks helped learning about adolescence, genital health, pregnancy, and similar concepts. However, they seemed to be very confident on the issue that social media disseminated this information. When the teachers were asked about the accessibility of internet among the students, the common response was that the students had access to internet, whether by parents' mobile, computer or friends' devices.

\section{Students May Misinterpret the Lessons and Practice Unethical Physical Relations in their Regular Life}

Even though this chapter does not describe the details of any sexual act, the teachers claimed that being open about these topics might lead students to being involved in physical relations, which were forbidden by religion. They claimed this was a reason to exclude such topics. Six of the eight teachers brought up this issue and claimed that the more these topics were openly discussed, the more social anarchies (in terms of unethical relations) were increased. This was evident in one of the teachers, as noted by Ms. Chowdhury's opinion, “... and that is why the unethical relations are increasing in the society. YouTube, Facebook has spoiled the learners, and they are having physical relations before they are mature. So the social anarchy has increased you know... the youth is on the way of being totally spoiled."

\section{Evolution and Contradiction with Religion}

We predicted that some schools might exclude evolution from the syllabus citing reasons that the evolution theory contradicted religion. However, only one of the eight teachers stated that evolution was not that necessary to teach, and he talked from a religious point of view. The other teachers were very delighted that the topic was included in the textbook Some stated that the survival of animals and plants, as well as the evolution of them should be elaborated on more in textbooks.

Ms. Begum believed that the theory of evolution had been denied by most scientists and therefore it had no reason to be in textbooks. When she was asked, on which point it was contradictory, she seemed to have only a vague understanding of the topic:

The evolution theory is rejected by the whole world. All scientists, all over the world, have rejected it. Why would 
we teach the students a false theory? Why was it included in textbook? You see, it contradicts our religion, why would we teach our students a false theory, which insults our religion?

From her opinion, it was clear that the theory was not approved by scientists and second she thinks, it will affect the religious views of her students. However, this chapter only focused on the survival instincts of animals. In no way did the chapter say anything against religion, so from her opinion it could be concluded that she might have less knowledge about the whole theory.

\section{Position of Curriculum Developers, Textbook Authors and Teacher Educators on Null Curriculum}

Data collected from the teachers' interviews were analyzed and certain themes were identified. Then, in phase 2, interviews were conducted with curriculum developers, textbook authors, and a teacher educator. They were asked to explore the teachers' opinions and give their own comments on the specific issues. The major findings are discussed below.

\section{Feeling "Uncomfortable" is Probable but not Expected from Teachers}

The teachers claimed that they felt uncomfortable talking with their students about topics such as genital health, reproduction, and pregnancy. The curriculum developers, teacher educator and textbook writers agreed with the teachers that talking about this topic might be uncomfortable since it was a new inclusion. According to Mr. Rahim:

Yes, there are some possibilities that the teachers might feel shy or not easy to talk about it. You have to understand; the teachers are also a part of the society. There are some social, local, and environmental barriers which cannot be found in writing [cannot be seen or found in any documents], but they exist. You cannot deny them. Teachers will feel uncomfortable; it's to some extent inevitable.

The chapter "the beginning of new life" included some topics those were culturally considered as sensitive. However, the widespread use of the internet and media was supposed to have decreased this discomfort from teachers. Yet, this sudden change in curriculum has had an impact on teachers. At the same time, Mr. Rahim also emphasized the fact that the teachers were going through professional development training for including new topics, so it was expected that this uncomfortable feeling of teachers would decrease. However, unfortunately, it still exists.

\section{Curriculum Demands these Topics to be Included}

Whether or not the teachers taught the students about adolescence, genital health and related topics, the curriculum demanded these topics be included in the textbook. In response of teachers being so rigid about teaching the topic, the curriculum developers and curriculum specialists think, it was as important as other topics and could not be left out. According to Ms. Rumana, "Not only because the developed countries included these topics, so we had to introduce them, but also the curriculum needs to be designed in a way that it provides necessary information in the proper age."

From the opinions of the curriculum developers, specialists and textbook writers, there were two main reasons for introducing this specific chapter regarding adolescence in Grades IX-X. The first one was the demand of knowledge about this topic in the age of Grades IX-X students, to make them scientifically literate. Another was to keep pace with the advancing world. The curriculum developers and experts also pointed to other benefits of inclusion of this chapter, such as addressing social issues such as child marriage, avoiding misconceptions, and superstitions regarding sexual and reproductive education.

\section{Teachers Can be Culturally or Socially Challenged}

Teaching or even talking about genital health, reproduction, evolution or pregnancy is not considered appropriate in Bangladesh society. So in a few cases, the teachers might feel challenged while taking decisions to teach these specific topics. Mr. Rahim thinks:

Even if the teacher wants to teach these topics in the class, the head teacher might not be in support to him. There are School Management Committee (SMC), guardians, local people, and the stakeholders who may have a different opinion on discussing these topics in public. The teacher might feel insecure about his image, or job. That might influence him to take decision to exclude the topics.

Both Mr. Rahim and Mr. Nisar think that the teachers were getting proper training. During the training, the teachers may seem to be convinced that they will talk about genital health and sex education. Nevertheless, when they get back to the classroom, there were no trainers, but a different environment than the training room. The local people, the guardians and even the other teachers' mindset have an influence on them. The environment and the location of the school, play a role here. The local people can be open-minded; however, sometimes they can hold different opinions on the discussion of socioscientific issues (SSI) openly. Hence, the teachers' decision might change.

\section{Possible Solutions to Prevent the Exclusion}

The topics in consideration were about natural human processes; there was nothing to feel shy while talking on these topics. The curriculum experts, teacher educator and textbook writers gave several possible solutions to overcome this problem so that these important but sensitive topics did not get excluded.

Ms. Tonima thinks respecting the human body and the biological processes is a way to include these topics easily. Every animal goes through these processes. The teachers can assure the students that there is nothing to feel uncomfortable or shy about and there is nothing to laugh or make chaos.

According to Mr. Nisar, relating these topics with the personal life experiences of students is a better way to introduce this topic. Every person goes through some experiences when 
entering the adolescence period. Mr. Rahim agreed with Mr. Nisar that students already have some experiences and following the constructive view and conceptual change model, the teacher's duty is to relate his/her personal experience with the textbook topic. The same argument applies when teachers say that the students already know this content from other sources like electronic media and social media; students might know, but the teacher has to confirm that all students have the common and correct information.

Ms. Nahida also suggested that the teachers should be trained specifically to teach these topics. Mr Rahim stated that there are several training programs organized by the Ministry of education such as teaching quality improvement, SMC Training, Head teacher training, Union Office training, Madrasa based training, and Mosque based training. He emphasized that the training of stakeholders is as important as teacher training. He highlighted, "Teacher training is not enough. A teacher is only a part of the whole education system. The relevant stakeholders, all of them including the society, locality, and the awareness should be spread in mass level."

Teacher educators asserted that all stakeholders need to be oriented about the inclusion of topics relating to genital health, reproduction, and other sensitive topics. Specifically, it has to be mentioned that this topic is included and teachers teach the topic for the betterment of the society.

Class IX-X is the Appropriate Time to Know about Pregnancy and Genital Health for the Students, and it Will Reduce Superstitions, Sexual Harassment, and Abuse to Some Extent

Curriculum experts and teacher educators argued that Grades IX and $\mathrm{X}$ are the appropriate time for inclusion of topics related to adolescence and sexual health. In the context of Bangladesh, the child marriage rate is still high, and in rural areas, students of Class IX-X are getting married in large numbers. Many students do not continue their study after their Secondary School Certificate Examination (SSC) exams. Hence, there are no further opportunities to them about such topics. Male students have many misconceptions and fantasies in this age, so introducing these topics formally in this class will help them gain the proper knowledge at the proper age. Apart from this, the topic includes topics such as mental health and mood swings during adolescence. It is assumed that the students of Class IX-X are in their adolescence period. Therefore, learning about these topics formally in class would help them and their friends to understand their psychological situations. As such, the teachers' claim that the topics were not appropriate for this age is not valid.

The interviewed teacher educator, textbook writers and curriculum experts believed inclusion of these topics would help to reduce a few social problems. For example, Mr. Rahim noted:

There are some problems in our society, which occurs only because of lack of awareness. These problems might be related to child marriage, superstitions about taste tube babies. Now, in our country, I haven't seen anyone encourage taste tube babies, neither in rural nor in urban areas. But once a student gets the exact knowledge about taste tube babies, he/she might be able to accept the scientific fact easily.

The natural human processes include menstruation of females and sperm production of males. Mr. Nisar thinks introducing these topics in textbook would reduce sexual harassment, rape, unnecessary abortion or unexpected pregnancy for a large number of students. He stated:

Sometimes, girls of this age are unaware of such topics and they get exploited. Suicide take place, death during pregnancy occurs. Even boys, who have less knowledge on this topic, marry or rape underage children, not knowing that their reproductive organs are not mature yet.

In most cases, the first menstruation of a female or first wet dream of a male causes unnecessary stress for the whole family. In addition, a lack of proper knowledge about the reproductive system and reproductive organs sometimes lead to unexpected occurrences. So including topics that elaborately describe the reproductive parts and organs, reproduction system would help young students to make better decisions. According to the curriculum developers, teacher educator and textbook writers, knowledge from the textbook with friendly discussions with teachers would help decrease rape and other social problems.

\section{DISCUSSION}

From the interview of the teachers, it was clear that the chapter titled "The Beginning of New Life" in Grades IX-X General Science was excluded from their classroom teaching. The students, however, differed in that opinion and they said there was no chapter left out from their textbook in classroom teaching. Possible reasons for this difference in opinions could be that the students might feel insecure to say anything that they think might go against their teachers. In addition, there is a possibility that they might have learnt these topics from home tutors and private tutors, so they did not find it excluded.

Teachers made several arguments in favor of excluding the chapter from classroom teaching. The teachers' view on teaching topics such as sexual and reproductive health, reproduction and evolution was influenced mainly by their upbringing, socio-cultural environment and their mindset. These issues were socially challenging for them to discuss in the classrooms. Such topics are referred to in literature as SSI (Sadler, 2004). Science educators offered various solutions for addressing the issue of excluding SSI in the classroom. These solutions can be based on scientific principles, theories and data, but the solutions cannot be fully determined by scientific considerations because these issues and potential courses of action associated with the issues are influenced by a variety of social factors including religion, politics, ethics, and other social values. In this context, to overcome the situation, not only the teacher, but also the society has to be open-minded 
enough to bring out the hidden or neglected topic to let the students achieve scientific literacy in the fullest sense. The problem raised by exclusion of these topics cannot be measured in any scale, but the result is quite visible. Hence, the whole society has to come forward to solve the issue.

The teachers were very forthright about the fact that teaching these topics was the duty of the parents. However, it cannot be stated with certainty that all the students in Bangladesh have parents or close family members who are well educated. Even if they did learn from family members, they acknowledged what students learned could not be assumed to be accurate.

The teachers also claimed that all their students had access to internet and they already knew the necessary information from sources such as social media, YouTube, and videos available on the internet. There are three issues here:

a. Not all students in Bangladesh have access to internet. Even if the students' home and/or schools have internet access, some families or school authorities do not allow young children to use the internet.

b. It cannot be ensured that the students are getting the correct information. Information about reproduction, evolution or any topic, in fact, can be found on the internet that is both authentic and inaccurate. As a result, there are possibilities that students might get distorted information about reproduction, misconceptions or unrealistic fantasies.

c. Sometimes, when the learning is not evaluated, it cannot be measured that the students have interpreted the information accurately. Even if the parents, family members or alternative sources gave the correct information about reproduction and genital health, the student might misinterpret this, and since the teachers are not evaluating the achieved knowledge, there might be a chance that the students have distorted fantasies or unrealistic thoughts on these.

The curriculum developers and textbook writers pointed out several impacts for excluding the real-life related topics such as genital health, reproduction, and changes during adolescence. The major impact on the students for excluding this topic was that the achievement of scientific literacy was being hampered. According to Goodrum (2007), one of the characteristics of a scientifically literate people is that they can make an informed decision about the environment and their own health and well-being. Therefore, students need to be able to make scientific decisions regarding their health, hygiene, and personal wellbeing. The chapter, "The Beginning of New Life" intends to help students develop understanding on these aspects. The learning objectives of the chapter include:

- Explain adolescence.

- Explain the causes of physical changes in adolescence.

- Describe the ways of adjustment to the physical and mental changes in adolescence.

- Explain the strategies of keeping good physical and mental health during adolescence.
- Explain health risk of marriage in adolescence and its effects.

- Explain the concept of test tube baby.

- Explain the way of determining sex.

- Explain the origin of life and the concept of biological evolution.

- Explain the concept of origin of new species on earth (NCTB, 2012. p. 104).

As noted, the chapter includes topics which are very much related to the students' personal life, their health and hygiene, and to some extent their decisions in their personal lives regarding pregnancy and other issues. It has been observed that knowledge on reproductive health issues such as HIV/AIDS, the fertile period, potential health risks of early pregnancy and contraceptives increased as a result of school based reproductive health education program (Bhuiya et al., 2004). Inclusion of such topics on reproductive health education would address social issues such as gender inequalities, sexual harassments, AIDS, and other sexually transmitted diseases (Moletsane, 2014). Moletsane further argues that without the requisite sexual and reproductive health knowledge, including knowledge of their rights and the resources available to them, girls' agency is compromised. Furthermore, they are not adequately prepared for life transitions that place them in environments, like universities, that are characterized by unequal gender norms, gender-based violence, and sexual violence. Therefore, it can be argued that exclusion of the above concepts is likely to cause a bigger problem in achieving scientific literacy and in decision-making of their real-life related matter.

\section{CONCLUSION AND RECOMMENDATIONS}

Educational research is conducted to inform policy, in terms of both mergings with the context and keeping pace with the advancing world. It is also expected that research findings will bring a change in classroom teaching practices. From the findings of the study, it can be concluded that teachers, as the main stakeholders responsible for implementing curricular intensions, lack the necessary understanding, skills and attitudes to teach some important content in the classroom. Professional development programs for Science teachers in Bangladesh need to address this issue seriously. Initial teacher education and continuous professional development programs in Bangladesh need to incorporate necessary content and pedagogical knowledge on SSI including adolescence and reproductive health issues to equip teachers with necessary knowledge, skills and attitude to teach SSI in classroom.

NCTB in Bangladesh is responsible for developing and disseminating curriculum, textbook and the teacher's guide. Curriculum dissemination programs conducted by NCTB should emphasize developing teachers' awareness, knowledge and pedagogical strategies to teach these issues. A clear guideline could also be given in the teacher's guide. Curriculum should be organized in a way that the SSI are 
incorporated in different chapters under different subjects instead of compiling them into a single chapter.

Teaching-learning activities are always influenced by assessment. Stakeholders in Bangladesh highly value high grades. When a topic is emphasized in examination, teachers tend to include it in their teaching. Therefore, the public examinations like Junior School Certificate, SSC need to include questions on the SSI to ensure that teachers teach them in classroom.

\section{REFERENCES}

Babbie, E. (2002). The Basics of Social Research. $2^{\text {nd }}$ ed. Belmont: Wadsworth/Thomson Learning.

Bhuiya, I., Rob, U., Chowdhury, A.H., Rahman, L., Haque, N., Adamchak, S., Homan, R., \& Khan, M.E. (2004). Improving Adolescent Reproductive Health in Bangladesh. Available from: https://www.pdfs. semanticscholar.org/08d5/69ee1603e205bfcfa412b8d7a4f964e47820. pdf. [Last accessed on 2017 Jun 19].

Creswell, J.W. (2008). Educational Research: Planning, Conducting, and Evaluating Quantitative and Qualitative Research. $3^{\text {rd }}$ ed. Upper Saddle River: Pearson Education, Inc.

Eisner, E.W. (1994). The Educational Imagination: On Design and
Evaluation of School Programs. $3^{\text {rd }}$ ed. New York: Macmillan.

Fensham, P.J. (1985). Science for All: A reflective essay. Journal of Curriculum Studies, 17(4), 415-435.

Gehrke, N.J., Knapp, M.S., \& Sirotnik, K.A. (1992). In search of the school curriculum. Review of Research in Education, 18, 51-101.

Goodrum, D. (2007). Teaching strategies for classroom learning. In: Dawson, V., \& Venville, G., (Eds.), The Art of Teaching Primary Science. Crow's Nest: Allen \& Unwin. p108-126.

Hildebrand, G. (2007). Diversity, values and the science curriculum. In: Corrigan, D., Dillon, J., \& Gunstone, R., (Eds.), The Re-Emergence of Values in Science Education. Rotterdam: Sense Publishers. p45-60.

Moletsane, R. (2014). The Need for Quality Sexual and Reproductive Health Education to Address Barriers to Girls'Educational Outcome in South Africa. Available from: https://www.brookings.edu/wp-content/ uploads/2016/06/EchidnaMoletsane2014Web.pdf. [Last accessed on 2017 Jun 19].

National Curriculum and Textbook Board (NCTB). (2012). National Curriculum for Primary Level-2012: Primary Science. Available from: http://www.nctb.gov.bd/document/primary_curriculum/8.\%20 ScienceCurri.pdf. [Last accessed on 2017 Jun 19].

Reiss, M. (2007). What should be the aim(s) of school education? In: Corrigan, D., Dillon, J., \& Gunstone, D., (Eds.), The Re-Emergence of Values in Science Education. Rotterdam: Sense Publishers. p13-28.

Sadler, T.D. (2004). Informal reasoning regarding socioscientific issues: A critical review of research. Journal of Research in Science Teaching, $41,513-536$ 